\title{
Partnerships and participation in conducting poverty-related health research
}

Linda Reutter Faculty of Nursing, University of Alberta, Alberta, Canada, Miriam J Stewart Faculty of Nursing, University of Alberta, and Scientific Director, Institute of Gender and Health, Canadian Institute of Health Research, Alberta, Canada, Kim Raine Faculty of Agriculture, Forestry and Home Economics, and Director, Centre for Health Promotion Studies, University of Alberta, Alberta, Canada, Deanna L Williamson Department of Human Ecology, University of Alberta, Alberta, Canada, Nicole Letourneau Faculty of Nursing and Canadian Research Institute for Social Policy, University of New Brunswick, Canada and Sharon McFall Boyle McCauley Health Centre, Edmonton, Alberta, Canada

Partnerships and participation are important principles of primary health care and increasingly are advocated in poverty-related health research. These concepts were central to our study of low-income Canadians' use of health-related services and supports. We created partnerships by including community members on the research team, establishing a community advisory committee, involving community agencies in recruitment and interviews, and obtaining stakeholder perspectives on the research findings. We fostered participation of low-income people by including their perspectives during the design and implementation of the study, reducing barriers for participation, and using peer interviewers. Despite the successes of these strategies for promoting partnerships and participation, challenges emerged in relation to maintaining involvement of stakeholders and ensuring adequate opportunities for research capacity building. Stakeholders and lowincome people identified policy and service delivery changes that would enhance accessibility to health-related services as well as potential barriers that influence change efforts. Participants emphasized the need to view poverty as 'everyone's business', which necessitates participation and partnerships with people living in poverty, with service providers, and with policy influencers. Our findings suggest, however, that people living in poverty encounter barriers to participation, and that further efforts are needed to obtain their input in the development of programmes, services, and policies. We recommend that primary health care research include community partners on the research team, community advisory committees and perspectives of policy makers and service providers. Researchers require adequate funding to develop and maintain partnerships with stakeholders, to train and support vulnerable people in developing skills and confidence as active research participants and to communicate the research to relevant stakeholders. We also recommend that evaluation of the participatory process be built into the research design.

Key words: participatory research; peer interviewers; poverty; primary health care; research partnerships

Partnerships and participation are key concepts of primary health care (PHC) (World Health Organization (WHO), 1978;2001). Maximum individual and community participation in identifying and addressing health needs is critical for

Address for correspondence: Dr Linda Reutter, Faculty of Nursing, 3rd Floor, Clinical Sciences Building, University of Alberta, Edmonton, Alberta, T6J 2G3, Canada. Email: Linda. reutter@ualberta.ca the development of appropriate, acceptable, and sustainable health programmes (Cornwall and Jewkes, 1995) and policies (Edwards, 1996). Powerlessness has been identified as an over-arching disease risk factor, while participation has proven to be health promoting (Wallerstein, 1992; Wilkinson, 1996). Furthermore, a population health approach that emphasizes the broad array of health determinants - most of which fall outside the health care sector - requires intersectoral and interdisciplinary partnerships and collaboration. 
Developing intersectoral and interdisciplinary partnerships is another PHC principle.

These principles of PHC increasingly are emphasized in conducting community-based research (Brodsky, 2001; Reid and Vianna, 2001; Flaskerud et al., 2002). Moreover, funders are requiring partnerships with those who can facilitate dissemination and utilization of research knowledge, as well as participation from those who will benefit from the research. Health researchers, particularly in the field of health promotion, have embraced participation and partnerships as important elements of capacity building (Flaskerud and Winslow, 1998; Reutter et al., 1998; Northway, 2000; Flaskerud et al., 2002). Indeed, professionals whose practice frameworks are built on a philosophy of PHC have advocated greater adherence to these principles in their research (e.g., Dickson, 2000; Community Health Nurses Association of Canada, 2003). Inclusion of these principles is particularly germane for research with vulnerable populations, because vulnerable populations, including people living in poverty, are often disempowered. Given the complexity of poverty and its relationship with other social determinants of health (e.g., social support, education, employment), intersectoral and interdisciplinary partnerships are crucial components of poverty-related research. These partnerships require participation from communities experiencing the issues and from organizations that can effect change (LeCompte et al., 1999).

In this article, we examine the successes and challenges of incorporating intersectoral and interdisciplinary partnerships and public participation in a Canadian study of low-income people's access to health-related services and supports. Access to health services for vulnerable groups is another key principle of PHC (Stewart, 2000).

Partnerships and participation in research can be viewed within the framework of participatory research. Participatory research seeks to improve the quality of life of participants by involving them in a process that uses their knowledge to seek solutions to their problems (Park et al., 1993, cited in Green et al., 1995). Participatory research has taken various forms; however, the approaches share six key principles and values (Minkler and Wallerstein, 2003). These are:

1) participation and co-operation of community members and researchers in a joint process;
2) identification of the research problem by the community;

3) collective learning and action;

4) flexible research methods that are appropriate for the community;

5) an empowering process for participants;

6) local capacity building (Green et al., 1995; Israel et al., 1998).

In a 'pure' form of participatory action research, action is built into the research design. Other studies, like our study with low-income people, lay the foundation for action by building partnerships with beneficiaries and stakeholders. Incorporating the expertise of low-income people should increase relevancy of policies and programmes, and foster empowerment, control, and change. Partners have a key role in moving research results toward action in policies, programmes, and practice.

\section{A Canadian study of low-income people's use of health services}

\section{Overview and context}

The purpose of our study was to identify the determinants of health services use from the perspectives of people living in poverty. Poverty is the greatest determinant of health, as it influences virtually all other determinants, including accessibility to health care (Federal, Provincial, and Territorial Advisory Committee on Population Health (FPT), 1996; WHO, 1997). We conducted our study in Edmonton, Alberta, Canada, a large urban centre, where at the time of data collection (1999-2000), about one-fifth of residents had incomes below the Statistics Canada low-income cut-offs, commonly viewed as a measure of poverty ${ }^{1}($ Lee, 2000$)$.

Most Canadian research examining the effect of income on the use of health services has focused on formal professional services, most notably medical care. We know less about factors that influence access to a broader range of healthrelated services and supports. The current study

\footnotetext{
${ }^{1}$ The LICOs are income levels at which Canadians, differentiated by family size and the population of their community of residence, spend $20 \%$ more of their income on basic needs than the average proportion spent by Canadians. Currently, families who spend more than $54.7 \%$ of their income on basic needs are living below the LICO. Low-income and poverty are used interchangeably in this article.
} 
explored low-income people's use of a range of health-related services and supports (including health promotion and illness treatment) and the factors that influenced their use. A deeper understanding of these factors will assist health professionals to target and tailor services, and to advocate policies that enhance accessibility. Accessibility to a broad range of services and supports that influence health is congruent with a PHC approach, which emphasizes the inter-relationship between social development and health.

In Phase I of the study, we conducted individual face-to-face interviews with 99 low-income people. In Phase II, separate group interviews were held with low-income people, service providers and managers, members of advocacy organizations, and public civil servants. The interview data were analysed using thematic content analysis.

Virtually all low-income participants reported using a broad range of formal health services (e.g., physicians, community health clinics, walk-in clinics, emergency departments) and informal community services (e.g., food banks, collective kitchens, child and family support services). Low-income people's ability to access services depended on proximity, affordability, convenience, and knowledge of their existence. Study participants reported major financial and structural barriers, problematic interactions with service providers, and inadequate information about services. Participants recommended changes to programmes and policies that would increase accessibility to and quality of services. A detailed account of the findings is reported elsewhere (Stewart et al., in press).

\section{Partnerships with relevant stakeholders}

In our project, we developed partnerships with people living in poverty, advocacy groups, service providers, and policy-influencers at all government levels. We used various strategies to incorporate these stakeholders in the research process.

\section{Inclusion of community members as partners on the research team}

One of the elements of participatory research is the relevancy of the research question to the community (Green et al., 1995). In contrast to most research, the impetus for our study was an issue identified by a member of a poverty advocacy group, who lived in poverty herself. She observed differences in the temporal patterns of health services use at a PHC agency and approached the service manager about investigating this issue. We invited these two individuals (hereafter referred to as community research partners) to join the interdisciplinary research team. The research team comprised seven academic researchers, representing the disciplines of health promotion, human ecology, nursing, and medicine.

The community research partners played a crucial role because of their personal and professional familiarity with the impacts of poverty on health, their links to the low-income community and other relevant stakeholders, and their commitment to empowerment and capacity building. Indeed, the community research partners suggested that low-income people be employed as interviewers to enhance individual and community research capacity. The community service manager secured her agency's commitment to co-sponsor the initial funding of the project. Her links with philanthropic organizations facilitated additional funding from community foundations, which do not typically provide funding to academic institutions. The community researchers also participated in selecting project staff and identifying advocacy organizations for the group interviews.

Establishment of a community advisory committee

We established a community advisory committee to guide the research process and to ensure its relevance for enhancing policies and services for low-income people. The 12-member committee included service providers, the director of an advocacy organization, senior representatives of provincial government sectors (health and social services), and five people living in poverty. The committee helped to screen and select project staff; develop criteria for hiring peer interviewers; recruit participants for the group interviews; review interview guides and preliminary analysis of data; and identify dissemination strategies. This committee met for the duration of the project, but more frequently during the first year, as we launched the study.

\section{Establishing partnerships with community agencies}

We developed partnerships with community agencies serving low-income people to implement 
the research and disseminate research findings. Initial involvement of community organizations occurred through input to the research proposal and letters of support. We also received letters of support from key policy influencers at national and provincial government levels, and from healthrelated service organizations. These community partners validated the need for and relevance of the research:

This project will deliver what decision makers need. It will most certainly be of compelling interest both at the provincial and national level.

We will be able to use these results to look at how we might improve our services, advocate for change, and work with low-income individuals to help them overcome problems associated with living in poverty.

Once the project was funded, community agencies participated in diverse ways. Five nongovernmental agencies played a key role in 'gaining access' to study participants. We conducted interviews at these agencies to enhance accessibility for peer (lowincome) interviewers and participants. Agency staff determined appropriate strategies for recruiting participants, provided space for the individual interviews, facilitated interviewees' payments, and provided support for interviewers (e.g., referral for interviewees in crisis). Staff members and managers themselves participated in the Phase II group interviews. We found that this partner agency support was crucial to the success of the study.

\section{Obtaining stakeholder perspectives on the research findings}

We conducted group interviews in Phase II to validate the findings of the initial phase and to seek input on how policies, programmes, and practices could be improved. We held four group interviews with people living in poverty (two with participants who had been interviewed in Phase I). The fifth group interview included government decisionmakers, representing community services, health, welfare, transportation, and justice. Another group comprised service managers from agencies serving low-income people, community health centres, and street outreach programmes. The seventh group interview included representatives from advocacy groups, such as employment centres, mental health associations, and consumer associations.

\section{Participation of people living in poverty}

\section{Ensuring inclusiveness of perspectives}

We used purposive sampling to recruit people with varied low-income situations (working poor, social assistance, unemployment) and demographic characteristics (gender, family composition, age, culture/ethnicity). Qualitative individual interviews using a semistructured interview guide provided opportunities for participants to relate their stories in their own words. Questions elicited perspectives on:

1) types of health-related services and supports accessed;

2) accessibility, acceptability, and availability of services and supports;

3) factors that influenced the use of services;

4) how services, programmes, and policies could be enhanced;

5) involvement and interest in action to effect change.

The Phase II group interviews with low-income people focused on how the results from Phase I 'fit' with their own experiences; how services, programmes, and policies could be improved; how lowincome people could be involved in influencing services, programmes, and policies; and audiences and strategies for dissemination. In these ways, we included the views of low-income people in diverse situations on a broad range of issues related to health-related services and supports.

\section{Fostering participation of low-income participants}

Gaining access to vulnerable populations is a major research challenge because of power inequalities between researchers and participants and the complexity of participants' lives (Demi and Warren, 1995; Flaskerud and Winslow, 1998; Heaman, 2001). To facilitate participation, agency staff informed their clients about the project, and we interviewed participants in agencies that they routinely accessed. To convey the value of their expertise and participation, we gave participants an honorarium and remuneration for child care and transportation costs. Peer interviewers further facilitated participation 
by decreasing power inequalities between interviewer and interviewee (LeCompte et al., 1999). The data transcripts revealed that interviewers were empathetic and spoke to participants from an 'insider's' perspective, reflected by such comments as 'these are tough things to talk about ... they're awfully hard issues to deal with;' 'that's a very common thing that I hear about.' Interviewers also clarified interview questions by providing relevant examples, when required. These strategies to enable participation, which have been used by others (Demi and Warren, 1995; Kelly and Cordell, 1996; Flaskerud and Winslow, 1998; Brodsky, 2001), were highly successful. We had an excellent response from low-income people expressing interest in the study.

\section{Education and capacity building of peer interviewers}

A major goal of participatory research is capacity building and education (Green et al.,1995). A unique aspect of this study was increasing the capacity of low-income people through training and participating as peer interviewers. Potential interviewers were recommended by community partners, the community advisory committee, and agencies serving low-income people throughout the city. The major criteria for selection were living on low or no income, and good listening and organizational skills. The selection committee included researchers, advisory committee members (including low-income people), and the project co-ordinator. Thirteen lowincome people, representing variability in geographic location, gender, cultural background, and language, completed the training sessions.

The training consisted of four 3.5-hour sessions and two follow-up sessions. To facilitate participation, we conducted training sessions at a central location during the early evening, and began each session with a meal. The first session included an overview of the context of poverty in Edmonton and Canada, the purpose of the project, and the overall research design and methods. Further training sessions incorporated discussions about ensuring confidentiality, scheduling interviews, determining eligibility of participants, obtaining informed consent, and using the interview guide (i.e., intent and content of questions, strategies to develop rapport and elicit information, and terminating the interview).
All training sessions used an informal discussion approach. We employed strategies to convey a warm and friendly atmosphere, including casual dress, to diminish the inherent power differences between researchers and trainees. We used a variety of teaching methods, including open discussion, short presentations, small group discussion, role-playing, and resource manuals. We gave trainees an honorarium and reimbursed them for transportation and child care expenses. Once interviewing commenced, we paid interviewers per interview conducted (plus transportation and child care if required) and for participation in the group interviews in Phase II.

Interviewers conducted a pilot interview, which was reviewed by a member of the research team. This feedback enhanced the interviewer's skills, provided affirmation, and instilled confidence. Academic members of the research team facilitated two follow-up sessions with interviewers to debrief issues and concerns, provide support, and facilitate learning. At the conclusion of the data collection, we provided the interviewers with 'certificates' and letters detailing specific knowledge and skills they had mastered.

Several peer interviewers continued their involvement with the group interviews in Phase II. To prepare them we held another training session, outlining the purpose and method of group interviews and their role. At the group interviews, some interviewers introduced the study and presented the findings, and others contributed to the discussions. Regardless of interviewers' roles, their participation added depth, poignancy, and relevancy to the group interviews. One participant in the advocacy group interview stated, 'I think what's really helpful, even in terms of the dynamics of this [meeting] today, is to have [peer interviewer] here and participating ... People speaking out right from their own personal experience is probably far more profound than all the research studies in the world.'

The interviewers also participated with the researchers in conferences and workshops. At two different national conferences (one academic and the other for service providers), peer interviewers spoke movingly about their roles in the project and the benefits gained from their participation. On another occasion, three interviewers represented the research team at a health forum seeking input on community health needs. 
On completion of the data collection, peer interviewers discussed their experiences, challenges, and recommendations for similar projects at a final meeting. Overall, the interviewers perceived their experiences very positively and reinforced the empowerment and capacity building fostered by the study. They maintained that involvement in the research enhanced their self-esteem and selfconfidence, and their organizational, communication, and listening skills. They spoke positively about being employed by the university (rather than having a 'welfare job'), working independently, interacting with agencies in a professional role (as opposed to a client role), and collaborating with other low-income interviewers. Many expressed hopes that the experience would help them find other gainful employment. A few interviewers did obtain other research positions; one has been employed quite consistently as an interviewer with a federal government agency.

\section{Partnerships and participation: successes and challenges}

\section{Maintaining involvement of stakeholders}

Several factors fostered participation of stakeholders. First, academic researchers' links to povertyrelated organizations in the community facilitated entry to agencies. Secondly, we selected project co-ordinators and research assistants who had strong interpersonal skills, knowledge of the community, and sensitivity to issues faced by low-income people and agencies serving them. These factors no doubt facilitated the development of trust among research staff, agencies, and participants (Reid and Vianna, 2001). Thirdly, community partners on the research team promoted the goals of participation and capacity building. Fourthly, the major funders of this project required community, policy, and service provider partners. Fifthly, the researchers' valuing of both process and outcome, and their adaptability to different points of view from community partners, facilitated participation.

In spite of these factors, building and maintaining relationships with community organizations was a major challenge in our study. This finding is reinforced by other researchers engaged in community-based participatory research (Cornwall and Jewkes, 1995; Buchanan, 1996; Minkler et al., 2002). It was particularly challenging to foster smooth relationships with personnel from the community agencies serving as interviewing sites. Some management issues included submitting names for recruitment, paying interviewers, storing recording equipment, retrieving interview tapes, and attending to concerns of interviewers and agency staff. Much of this work fell to a part-time project co-ordinator, whose hours had to be increased to full-time during the early stages of data collection.

A further challenge was maintaining the full participation of the community advisory committee throughout the project. This was due in part to members' time constraints. Pressure from funders of nonprofit agencies to increase accountability, coupled with increased administrative workload, meant that managers were working well over $40 \mathrm{~h} /$ week. Representatives from government and public agencies were sometimes absent from meetings, due to last minute demands. As noted by others (e.g., Minkler et al., 2002), the first priority of community-based organizations is service commitment, not research.

The philosophy and culture of the community agency boards and staff also may have influenced stakeholder participation. Board members may undervalue manager participation in research initiatives because they do not recognize benefits of academic-community partnerships. Agency staff may view research as a 'frill' and not relevant to their everyday experiences. As our community research partner pointed out, these perceptions mean that managers who become involved in research can find themselves 'out on a limb hoping no one will saw off the branch.'

Finally, participation challenges may be related to inadequate time and resources to adequately nurture researcher-community relationships. Lindsey and McGuinness (1998) identify strategies to keep members involved: regular updates, adherence to time frames, records of discussions, easy access, flexible times, and refreshments. We attempted to incorporate some of these strategies. However, in the latter phase of the project, we maintained lessfrequent contact with the committee, due in part to changing project staff.

As researchers, we should recognize power differences among stakeholders to enable free dialogue. This was particularly important at community advisory committee meetings, which policy decision-makers, administrators, low-income people, and researchers attended. We held meetings at a 
community location, rather than the university, to increase comfort for community representatives. The composition of the committee ensured that lowincome people's perspectives were represented. However, less articulate participants expressed some discomfort, and, occasionally, comments were dismissed by those occupying positions of power. The research team's efforts to create an equitable, respectful environment were not always successful.

The two community research partners identified challenges unique to their roles. They experienced a steep 'learning curve' in terms of the language, process, timing, and context of research. At times, they worried that their original research ideas might be derailed. Although they received support and encouragement from each other, academic researchers need to build in mechanisms for regular discussion of the experiences, needs, and perceptions of all team members (Green et al., 1995). Israel et al. (2003) advocate ongoing evaluation of the implementation of participatory principles.

\section{Capacity building}

Co-learning (by all participants and stakeholders) and capacity building are important principles in community-based participatory research (Israel et al., 2003). One of the major avenues for capacity building in our project was hiring and training low-income people as interviewers. As indicated earlier, this approach appeared to foster capacity building. Nevertheless, interviewers identified several challenges. They felt burdened in being 'too close to the problems' they were hearing in the interviews, yet powerless in 'not being able to help these people.' Other researchers working with vulnerable populations (Demi and Warren, 1995) have described this reaction. Given that the interviewers themselves were experiencing the effects of poverty, their emotional responses were likely more marked. Others voiced uncertainty about what benefits would accrue in policies and programmes. During the training sessions, we attempted to inject some realism into 'ideal' expectations of the research outcomes. The task becomes one of balancing an optimistic rationale for carrying out the study with the reality that study results may not necessarily lead to immediate and significant change (Cornwall and Jewkes, 1995). Interviewers also identified issues related to delayed payments in the early phases of the project (due to logistical difficulties), which was very important as they relied on these funds to make crucial payments in their day-to-day lives.

Training lay interviewers was also challenging for the researchers. We did not anticipate the time and resources required for the training and ongoing support of the interviewers, and therefore had to extend the training period. We found it challenging to present the basics of interviewing within a limited time period to people who had little or no research experience. This experience was far different from guiding students who have academic research preparation.

Validity of data was both enhanced and limited by employing peer interviewers. Peer interviewers facilitated engagement and engendered trust and openness during interviews with low-income participants. However, in our attempt to make it easier for the inexperienced low-income interviewers, the interview guide was more structured than is usual for qualitative interviewing. Interviewers' inexperience with the use of probes may also have influenced the quality of data collected.

Another challenge related to the life situations of the interviewers. Although the researchers had previously worked with people living in poverty, we were now faced with 'coworkers' who had very complex lives and whose ability to cope was often precarious. We recognized that many contingencies could derail them from the priorities of the project, which necessitated realistic expectations around time lines. We also struggled to determine our appropriate role in assisting these low-income people during crises. This professional dilemma, highlighting the differential in power and privilege between researchers and participants, also has been reported by others (e.g., Dickson, 2000; Brodsky, 2001).

A further challenge relates to the researchers' role in facilitating capacity building beyond the immediate needs of the research. Once we got to know the interviewers, we felt a greater commitment to supporting their continued learning and employment opportunities. We wondered how their competence could be further enhanced and who should facilitate this learning. However, when we asked the interviewers near the end of the project if they would like us to assist them in transferring specific skills and knowledge gained in the project to other work situations, they did not express interest. It might have been helpful at the outset to have an open dialogue to determine their 
personal goals for participation in the project, and related needs for support.

\section{Implications for primary health care practice and programmes}

Stakeholders in Phase II identified policy and service delivery changes that would enhance accessibility to health-related services, and potential barriers in effecting these changes. Some believed that senior civil servants have limited freedom to bring about change, and advocated grassroots activism, intersectoral collaboration, and partnerships with government and nongovernmental stakeholders. Civil servants emphasized that advocates of poverty-related policies need to understand the political system. Participants promoted a paradigm shift, whereby poverty is seen as 'everyone's business,' and partnerships that involve people living in poverty and various stakeholders:

To systematically move the consumers up the participation chain ... to move people ... to increasing participation in how those services are actually delivered, to in fact designing the system and the services at the beginning.

Everybody's got to be involved in making changes, so somehow we've got to shift the paradigms so that within communities it's everybody's business. So it's not about 'we're going to help you' or 'you come and join us,' it's about 'this is all of our problem, this belongs to all of us.'

Our interview data suggest that people living in poverty are interested in working to bring about change that fosters access to supports for health. About one-third of participants said they had provided input regarding the delivery of services or advocated for policy changes. However, almost half had not provided input because they were not afforded opportunities or thought their input would not lead to desired change. They anticipated little responsiveness to their concerns, and believed that a collective voice was needed. The following quotes exemplify their feelings of powerlessness:

I just didn't think it would do any good. A lot of times people don't care for lower income people, and you say something to them, it just goes in one ear and out the other because they don't give a damn. I guess I just don't think that my views would be heard.

I find that you go to the government forums, they're just there to superficially let you think you're having a say and then they ignore you totally.

I've not been aware of what opportunities there are for me or what avenues I'm supposed to use to make that input.

About half of interviewed participants confirmed that they would like to provide input to policies and programmes, and suggested strategies such as communicating their concerns in writing, signing petitions, focus groups/meetings, and committees/ working groups. Overall, these findings suggest that further efforts are needed to foster participation of people living in poverty to enhance their accessibility to health-related services and supports.

Funding limitations precluded the incorporation of an action component in this particular study. Instead, its intent was to lay the foundation for intervention/action in service and policy domains through the establishment of partnerships with relevant stakeholders who could facilitate change. The first step in building this foundation was consciousness-raising among stakeholders in the Phase II group interviews. We presented the findings of the Phase I interviews to increase participants' knowledge and awareness of low-income people's needs for accessibility of health-related services and supports. These group sessions provided a forum for dialogue regarding 'where to go from here.' In these groups, we invited participants to provide input on needed changes and improvements to services and supports. We asked them to reflect on their agencies' potential involvement in facilitating these changes, as well as how people living in poverty could participate. Participants frankly discussed issues and frustrations faced in service delivery and policy-making, including an already overburdened service delivery system and moving beyond problem identification.

Another step toward action is the dissemination of findings beyond the academic community to audiences who have a key role in influencing and developing policies and programmes. We sent interim reports and one-page research updates to advisory committee members, relevant community 
agencies, and the Minister and Deputy Minister of Health. The final results of the study were disseminated to Phase II participants, participating agencies, funders, and those who provided letters of support. We prepared booklets highlighting the findings in accessible and attractive format and detailed research reports. The final report of the study is available on the web site of the major funder and the principal investigator.

We also presented the study findings at conferences for academic researchers and community service providers. In addition, the project co-ordinator and one peer interviewer participated in a radio interview, and another peer interviewer published an article in a newsletter focused on poverty issues. As indicated earlier, the interviewers and researchers together presented the findings at several public forums, and provided input at a community health council forum. These dissemination activities to various audiences increased knowledge of the challenges low-income people face in accessing health-related services and supports, thereby increasing the potential for action.

Our collaboration with low-income people illustrated to service providers and researchers how participatory elements can be incorporated into the research process. Moreover, the partnerships established between researchers and community partners in this particular study led to collaborations in other studies directed toward enhancing the well-being of people living in poverty. For example, in one study, youth, service providers and academic researchers collaborated in a very successful support intervention for homeless youth.

Finally, the capacity-building experienced by the low-income interviewers may also be viewed as laying the foundation for action. The knowledge, skills, and confidence gained by the interviewers increase the likelihood that they will participate in additional community initiatives to improve lowincome people's quality of life. In short, our strategies to build partnerships and participation could enhance the lives of low-income people through improved programmes and policies.

\section{Implications for primary health care research}

Health researchers who affirm the principles of PHC need to incorporate these principles into the research process. This Canadian study attempted to incorporate three key PHC principles. The study's aim was to enhance accessibility of vulnerable groups to health-related services. The research design emphasized two other principles: public participation, and intersectoral and interdisciplinary partnerships. Several recommendations can be drawn from our experience.

In this study, participation of multiple stakeholders ensured the relevance of research to the needs of people living in poverty and to those who enable accessible, acceptable services and supports. Moreover, incorporating low-income people as interviewers enhanced data validity, built individual and community research capacity, and was empowering. We therefore recommend that poverty-related research should include community partners on the research team (those living in poverty and those working with low-income populations), community advisory committees, and perspectives of policy makers and service providers.

Nevertheless, the implementation of participatory methods is challenging. Participatory research is very resource intensive, if the process is to be truly participatory (Lindsey and McGuinness, 1998; Dickson, 2000; Minkler et al., 2002; Israel et al., 2003; Stoecker, 2003). Therefore, we recommend that researchers secure adequate funding to:

1) develop and maintain partnerships with stakeholders and agencies;

2) train and support vulnerable people to develop the skills and confidence to become active participants in the research;

3) communicate the research to relevant stakeholders.

We further recommend that evaluation of the participatory process be built into the research design. This is particularly important when there are differences in power relations among stakeholders, community research partners, and academic researchers. It is important to monitor regularly participants' understanding of the research process, the extent to which their interests and goals are being met, and the responsiveness of team members to each other's needs and concerns. Open discussion of issues could increase commitment from, and benefits for, partners. Clearly, partnerships and participation are key ingredients of success for PHC research focused on vulnerable populations, such as people in poverty. 


\section{Acknowledgements}

The following Funding Sources are gratefully acknowledged: Canadian Health Services Research Foundation, Alberta Heritage Foundation for Medical Research, Boyle McCauley Health Centre, Edmonton Community Lottery Board, Health Canada (Ontario), United Way.

We acknowledge the contributions of other members of the research team: Doug Wilson, M.D., Janet Fast, PhD, Deana Shorten, Jeff Masuda, MSc., and the peer interviewers.

\section{References}

Brodsky, A. 2001: More than epistemology: relationships in applied research with underserved communities. Journal of Social Issues 57, 323-35.

Buchanan, D. 1996: Building academic-community linkages for health promotion: a case study in Massachusetts. American Journal of Health Promotion 10, 262-69.

Community Health Nurses Association of Canada (CHNAC). 2003: Community health nursing standards of practice. www.communityhealthnursescanada.org/Standards \%20of \%20Practaice.pdf. Retrieved August 2005.

Cornwall, A. and Jewkes, R. 1995: What is participatory research? Social Science and Medicine 41, 1667-76.

Demi, A. and Warren, N. 1995: Issues in conducting research with vulnerable families. Western Journal of Nursing Research 17, 188-202.

Dickson, G. 2000: Participatory action research: theory and practice. In Stewart, M.J., editor, Community nursing: promoting Canadians' health, second edition, Toronto, ON: Harcourt Canada, 542-63.

Edwards, R. 1996: Building healthy public policy. Evaluation in health promotion series: Canadian and international perspectives. Toronto, ON: Centre for Health Promotion, University of Toronto and ParticipACTION.

Federal, Provincial, and Territorial Advisory Committee on Population Health. 1996: Report on the health of Canadians. Ottawa: Minister of Supply and Services Canada.

Flaskerud, J., Lesser, J., Dixon, E., Anderson, N., Conde, F., Kim, S., Koniak-Griffin, D., Strehlow, A., Tullmann, D. and Verzemnieks, I. 2002: Health disparities among vulnerable populations: evolution of knowledge over five decades in Nursing Research publications. Nursing Research 51, 74-85.

Flaskerud, J. and Winslow, B. 1998: Conceptualizing vulnerable populations health-related research. Nursing Research 47, 69-78.

Green, L.W., George, M.A., Daniel, M., Frankish, C.J., Herbert, C.J., Bowie, W.R. and O'Neill, M. 1995: Study of participatory research in health promotion. The Royal Society of Canada: Institute of Health Promotion Research, University of British Columbia.

Heaman, M. 2001: Conducting health research with vulnerable women: issues and strategies. Canadian Journal of Nursing Research 33, 81-86.

Israel, B., Schulz, A., Parker, A. and Becker, A. 1998: Review of community-based research: assessing partnership approaches to improve public health. Annual Review of Public Health 19, 173-202.

Israel, B., Schulz, A., Parker, E., Becker, A., Allen III, A. and Guzman, J. 2003: Critical issues in developing and following community based participatory research principles. In Minkler, M., Wallerstein, N., editors, Community-based participatory research for health. San Francisco, CA: John Wiley \& Sons, 53-76.

Kelly, P. and Cordell, J. 1996: Recruitment of women into research studies: a nursing perspective. Clinical Nurse Specialist 10, 25-28.

LeCompte, M., Schensul, J., Weeks, M. and Singer, M. 1999: Researcher roles and research partnerships. Walnut Creek CA: AltaMira Press (Sage).

Lee, K. 2000: Urban poverty in Canada. A statistical profile, Ottawa: Canadian Council on Social Development.

Lindsey, L. and McGuinness, L. 1998: Significant elements of community involvement in participatory action research: evidence from a community project. Journal of Advanced Nursing 28, 1106-14.

Minkler, M. and Wallerstein, N. 2003: Introduction to community based participatory research. In Minkler, M., Wallerstein, N., editors, Community-based participatory research for health. San Francisco, CA: John Wiley \& Sons, 3-26.

Minkler, M., Fadem, P., Perry, M., Blum, K., Moore, L. and Rogers, J. 2002: Ethical dilemmas in participatory action research: a case study from the disability community. Health Education and Behavior 29, 14-29.

Northway, R. 2000: The relevance of participatory research in developing nursing research and practice. Nurse Researcher 7, 40-52.

Reid, P. and Vianna, E. 2001: Negotiating partnerships in research on poverty with community-based agencies. Journal of Social Issues 57, 337-54.

Reutter, L., Neufeld, A. and Harrison, M.J. 1998: Nursing research on the health of low-income women. Public Health Nursing 15, 109-22.

Stewart, M.J. 2000: Framework based on primary health care principles. In Stewart, M.J., editor, Community nursing: promoting Canadians' health, second edition, Toronto, ON: W.B. Saunders, 58-82.

Stewart, M.J., Reutter, L., Makwarimba, E., Rootman, I., Williamson, D., Raine, K., Wilson, D., Fast, J., Love, R., McFall, S., Shoten, D., Letowneau, N., Hayward, K., Masuda, J. and Rutakumwa, W. Determinants of health service by low-income people. Canadian Journal of Nursing Research. (in press).

Stoecker, R. 2003: Are academics irrelevant? Approaches and roles for scholars in community-based participatory research. 


\section{Linda Reutter et al.}

In Minkler, M. and Wallerstein, N., editors, Communitybased participatory research for health. San Francisco, CA: John Wiley \& Sons, 98-112.

Wallerstein, N. 1992: Powerlessness, empowerment, and health: Implications for health promotion programs. American Journal of Health Promotion 6, 197-205.

Wilkinson, R. 1996: Unhealthy societies. London: Routledge.

World Health Organization. 1978: Primary health care: report of the international conference on primary health care, Alma-Ata, USSR. Geneva: WHO.
World Health Organization. 1997: The Jakarta declaration on health promotion into the 21st century. http://www.who.int/ hpr/archive/docs/jakarta/english.html. Retrieved August 2005.

World Health Organization. 2001: Health for all in the twentyfirst century. Geneva: WHO. 